\title{
Die Godsdiensklousule in die Transvaalse Onderwyswetgewing.
}

1.

Ons kan die Transvaalse Godsdiensklousules nie goed verstaan sonder kennis te dra van wat in Engeland en in Kaapland aan die gang was nie. Met ander woorde, die geskiedenis van die Onderwyswetgewing in die Transvaal vereis 'n studie van die betrokke wetgewing in Ka:apland, vanwaar die Trekkers gekom het en vanwaar daarna nog steeds invloed op die Transvaal uitgegaan het. En Kaapland as Britse Kolonie het weer op sy beurt aangesluit by die moederland. Die invloed van die Engelse Onderwyswetgewing is op Kaapland en deur Kaapland weer op Transvaal baie merkbaar. Dit geld vir die neëntiende sowel as vir die twintigste eeu.

Maar by 'n ondersoek na die verloop van wetgewing op die gebied van die godsdiens op skool moet ook in die gedagte gehou word die feit van die Hollands-Afrikaanse tradisie wat uit die tyd van die N.O.I.C. aan die Kaap voortgesit is in die neëntiende eeu. By die voortsetting van die Christelik-nasionale tradisie kom by die invloed direk en indirek van Nederlanders wat in die Transvaal bly belang stel het en van die kontak van die Transvaal self met Nederland.

Die Hollands-Afrikaanse tradisie ten opsigte van die onderwys was 
'n Christelik-Gereformeerde skool en onderwys, 'n soort van Gereformeerde Staatskool, 'n skool waarin die godsdiens as vak en as stuwende krag die hele onderwys bepaal het. In hierdie gees en rigting het die Hollands-Afrikaanse Voortrekkers grootgeword en dit is die beskouing wat hulle met hulle saamgeneem het na die verre Noorde. Ons sal dit dan ook weer raak loop in die Transvaal tot 1872 .

2.

Die neëntiende eeu was vir Suid-Afrika soos vir Europa 'n eeu van die finale verbreking van die mag van die Kerk op staatkundige en ook op opvoedkundige gebied. Die Christelik-Gereformeerde skool sou algaande verdwyn en die plek daarvan ingeneem word deur 'n nie-denominasionale skool, 'n skool bo geloofsverdeeldheid, 'n skool sonder belydenis in die kerklike sin van die woord.

In Suid-Afrika is dit op die erf van die onderwys ingelui deur kommissaris-generaal J. A. de Mist wat in 1804 aan die Kaap 'n Skoolorder uitgevaardig het wat die nuwe skoolgees en -rigting ingevoer het en wat dwarsdeur die neëntiende en die twintigste eeu die onderwys bepaal het. De Mist het die gees van die Franse Rewolusie en die liberalisme vertolk en gevestig.

Wat die Godsdiensonderwys betref, het die Skoolorder die volgende neergelê. Dit maak voorsiening vir „onderwys in die eerste beginsels van die Christelike Godsdiens, soveel moontlik na leiding van die Kerkgenootskap, waartoe die ouers van die kinders behoort of behoort het". In sy Kerkorde omskryf hy sy ideaal so: „die openbare skool strek tot die onderwysing van die jeug en behoort nie tot enige besondere Kerkgenootskap nie. Dit is ' $n$ kweekplek om goeie burgers vir die Staat te vorm, en as sodanig staan dit onder die onmiddellike toesig en bestuur van die Goewerment". De Mist het dus gesoek na die volkome skeiding tussen Kerk en Skool en na die verwêreldliking van die onderwys as middel tot algemene volksverligting.

Met die oorname van die Kaap deur die Engelse is die poging tot verwêreldliking en denasionalisering van die Hollandse skool verder deurgevoer. Die Godsdiens is geleidelik op die agtergrond geskuif. Skotse predikante is in die Kaap ingevoer. Hulle het van Skotland saamgebring die idee van 'n "gewetensklousule" in die godsdiensonderwys. Die Skotse „General Assembly” het naamlik reeds in 1829 neergelê dat onderwysers geen godsdiensonderrig moet opdring aan kinders 
van Rooms-Katolieke ouers, 'n onderrig waarteen hul ouers of priesters besware het nie.

Die Kaapse Regering het in 1839 by Goewermentsmemorandum onder datum $23 \mathrm{Mei}$ bepaal dat godsdiensonderrig sal omvat daelikse lees uit die Bybel op 'n tyd daarvoor afgesonder, dat alle geleentheid aan leerlinge gegee sal word om die kategetiese onderrig van hul eie predikante (pastors) by te woon en dat as ouers gewetensbesware teen die deelname van hul kinders aan die godsdiensoefeninge van die skool het, aan sulke kinders op behoorlike aansoek vrystelling van bywoning van die oefeninge gedurende die skoolure gegee sal word, dat die eerste skoolperiode vir die oefening afgesonder sal word. In Kaapland vorm dit die eerste „Gewetensklousule” van amptelike kant afgekondig.

Op 23 Februarie 1863 is aan die Kaapse Regering deur 'n onderwys. kommissie onder voorsitterskap van adv. E. B. Watermeyer sekere aanbevelings gedoen na 'n omvangryke en indringende ondersoek van die onderwystoestande. Die aanbeveling oor die Godsdiensonderwys wys reeds hoever die openbare skool van die ou Gereformeerde Staatskool afgewyk het: Bestuurders van skole kan voorsiening maak vir die onderrig van leerlinge in die beginsels van die Christelike godsdiens op 'n tyd daarvoor en vir hulle afgesonder buite en behalwe die gewone skoolure, en geen leerlinge sal verplig word om aanwesig te wees op daardie uur vir godsdiensonderrig sonder die toestemming van hul ouers of voogde nie. Die aanbeveling is verwerk in die Kaapse Onderwyswet No. 3 van 1865 in Klousule 7: Die beginsel van nie-denominasionale godsdiensonderrig is neergelê; dit is ook bepaal dat die plaaslike skoolkommissies voorsiening mag maak vir godsdiensonderrig buite die gewone skoolure, maar geen leerling kan verplig word om die lesse by te woon sonder die toestemming van ouer of voog nie.

Die Wetgewing het die volle ondersteuning gehad van alle liberaalvoelende mense. Maar die gewone Afrikaner onder leiding van enkele ortodokse predikante was skerp daarteen gekant.

In 1870 het in die ou moederland-Engeland-'n uiters belangrike ontwikkeling op onderwysgebied gekom. 'n Nuwe Onderwyswet, rakende veral die laer onderwys, het tot stand gekom. Die Wet het o.a. die stigting van skoolrade in Engeland neergelê. Die skoolstryd in Engeland het gegaan veral oor die godsdiensonderrig op of deur die skool. Hierdie Elementary Education Act bevat vir ons doel twee uiters belangrike Klousules. Klousule 7 is die sg. Gewetensklousule en lui: 
"It shall not be required, as a condition of any child being admitted into or continuing in the school, that he should attend or abstain from attending any Sunday School, or any place of religious worship, or that he should attend any religious observance or any instruction in religious subjects in the school or elsewhere, from which observance or instruction he may be withdrawn by his parent, or that he shall, if withdrawn by his parent, attend te school on any day exclusively set apart for religious observance by the religious body to which his parent belongs". Die tweede Klousule is nog belangriker. Dit is bekend as die Cowper-Temple Clause (na die naam van die voorsteller daarvan in die Britse Parlement) en beheer die aard van die godsdiensonderrig op skool. Dit is Klousule 14(2) van die Wet: „No religious catechism or religious formulary which is distinctive of any particular denomination shall be taught in the public elementary school." Dit is die beruggeworde "nie-dogma-klousule" in die godsdiensonderwys.

Hierdie twee wette--die Kaapse van 1865 en die Engelse van 1870 -was goed bekend aan twee manne wat in die Transvaalse onderwys 'n belangrike rol sou speel: ds. T. F. Burgers en ds. S. J. du Toit.

3.

Ons kom nou-met die historiese agtergrond-tot die ondersoek van die Godsdiensklousules in die Transvaalse Onderwyswetgewing.

Ons vind hier tot 1872 'n voortsetting van die tradisie van die Hollandse Afrikaner ten opsigte van die onderwys van sy kind. Voor 1852 was alle onderwys heeltemal ongeorganiseer. Ouers het self of deur rondtrekkende meesters hul kinders die nodige onderrig gegee. Die hoofinhoud daarvan was die godsdiens, lees, skryf, syfer.

Die eerste vaste reëling van die onderwys het gekom met die eerste predikant, ds. D. van der Hoff, en die eerste onderwysers, H. v.d. Linden, J. W. Spruyt en W. Poen. In die eerste wetlike reglement vir die onderwys in Transvaal, opgestel deur Van der Linden, word in Artikel 3 net neergelê dat die leervakke sal wees lees, skryf, rekene en ander vakke, alles met 'n godsdienstige strekking. Die onderwysers is deur dip. Kerkraad goedgekeur en van hulle is verwag om minstens twee maal per week katkisasie te hou vir diegene wat as lidmate van die Kerk wil aangeneem word. Kerk en Skool het so innig saamgewerk dat daar geen sprake was van 'n Godsdiensklousule vir die skool nie. 
Volgens Artikel 24 van die Grondwet van 1858 van die Transvaalse Staat sou daar vir die onderwys voortaan van regeringsweë voorsiening gemaak word sodat onderwyssake uit die beheer van die plaaslike Kerkrade in die van die Regering sou oorgaan. Hier begin die voorstadium van 'n Gewetensklousule vir die Transvaalse onderwys. 'n Skoolkommissie is vir Potchefstroom benoem wat op versoek van die Regering op 19 April 1859 'n nuwe onderwysreglement vir die Transvaal opgestel ket. In Artikel 8 word die gewone skoolvakke genoem, maar bygevoeg word Bybelse Geskiedenis en die sing van Psalms en Gesange. Artikel 26 is reeds 'n voorloper van die Godsdiensklousule van later: alle goewermentsonderwysers moet belydende lidmate van die Nederduits Gereformeerde (Hervormde) Kerk wees. In Artikel 27 van die Grondwet word onderwys en godsdiens saamgevoeg en beskou as nasionale funksies

In Februarie 1866 het die Volksraad 'n nuwe onderwyswet vir die Transvaal aangeneem. Daarin word onder die Reglement van die Algemene Skoolkommissie neergelê dat die lede lidmate moet wees van 'n Protestantse kerk. Dieselfde bepaling geld ook die lede van plaaslike Skoolkommissies volgens hul Reglement. In die Reglement vir die Goewermentsonderwysers word weer eens bepaal dat alle onderwysers lidmate van die Protestantse Kerke moet wees. Onder die leervakke word genoem veral sang (Psalms en Gesange) en Bybelse Geskiedenis.

Met die koms van president T. F. Burgers in 1872 begin die eintlike behoefte aan 'n Godsdiensklousule in die Onderwyswet.

Ds. Burgers was predikant van die Ned. Ger. Kerk van Hanover. In Kaapland het hy hom reeds geskaar aan die kant van die sg. liberale predikante. Hy was 'n voorstander van die Kaapse Onderwyswet van 1865 en 'n ondersteuner van die godsdiens-bepalinge van die Engelse Elementary Education Act van 1870. Dit sal niemand dus verbaas dat hy in sy Skoolwet No. 4 van 1874 radikaal afgewyk het van alle vroeëre reëlings nie. In die Inleiding tot die Wet word verklaar dat die inrigting van die openbare onderwys met eerbiediging van elkeen se godsdienstige begrippe deur die Wet gereël word. In Klousule 3 van die Voorstel Wet ontbreek as skoolvak Bybelse Geskiedenis of enige vorm van godsdiensonderrig. In sy Voorstel Wet Artikel 26 het dit gelui: „Geen Godsdienst-onderwijs wordt in de Schooluren gegeven; echter zullen de schoollokalen buiten de schooluren met goedvinden van de Schoolcommissien, daartoe beskikbaar zijn voor Godsdienstleeraars 
of onderwijzers". In Artikel 51 van die Voorstel is die saak verder so uitgebrei: „De onderwijzers(-essen) zullen zich onthouden van iets te doen of te laten dat strijdig is met de eerbied verschuldigd aan de godsdienstige begrippen van andersdenkenden, van het geven van onderwijs in de Godsdienst gedurende schooluren, en er zich zelfs buiten de schooluren niet mede in laten, tenzij op uitdrukkerlijk verzoek van de ouders of voogden der kinderen". Die Volksraad was nie te vind vir die bewoording van die Voorstel nie, en na heftige besprekinge is Klousule 26 van die Wet so gestel: „Geen Godsdienst-onderwijs wordt in de schooluren met goedvinden der schoolcommissien, daartoe beschikbaar zijn voor Godsdienst-leeraars of onderwijzers, zullende verder in iedere school in de Bijbel gelezen en in de Bijbelgeschiedenis onderwezen worden". Artikel 51 van die Voorstel het so onveranderd gekom as Klousule 51 van die Wet.

Die kort tussenspel van 'n Engelse beheer het net een betekenis in hierdie verband-die stelling van die Engelse "Conscience Clause”. Die Britse nuwe Superintendent van Opvoeding, dr. J. Vacy Lyle, het in sy voorgestelde Onderwyswetgewing die saak van die godsdiensonderrig noukeurig en uitvoerig gestel. Die kort saamvatting daarvan is dit: Godsdiens vorm 'n essensile deel van die skoolwerk; die onderrig daarin moet plaasvind aan die begin of die einde van die skooldag en 'n bepaalde periode moet op die rooster daarvoor aangegee word; dit sal omvat die lees van die Bybel, Bybelgeskiedenis en verklaring van die Christelike beginsels; leerstellige onderrig word nie uitgeskakel nie maar die onderwyser moet hom bepaal tot die algemeen aanvaarde Skrifbeginsels en sy onderrig so inklee dat andersdenkendes nie gekwets of geindoktrineer word nie. Lyle voel dus vir die sg. „neutrale dogma”. Hy voeg verder by die bekende „Conscience Clause” van die Engelse Wet van 1870: Geen leerlinge sal verplig word om an enige godsdienstige verrigtinge deel te neem of onderrig in die godsdiens by te woon nie; enige leerling mag deur sy ouer of voog daaraan onttrek word, sonder om enige ander voordeel van die skool te verbeur. Onder die skoolvakke noem Lyle die Bybelgeskiedenis eerste.

Met die herverkryging van sy onafhanklikheid en die benoeming van ds. S. J. du Toit as Superintendent van Opvoeding in 1882 , tree die Transvaal 'n nuwe en stewige tydperk in sy onderwysgeskiedenis in. Ds. Du Toit het die Kaapse Wet van 1865 geken en verwerp, en hy het ook kennis gedra van die Engelse Wet van 1870 en die Skotse 
Wet van 1872, maar ook van die Nederlandse stryd om ChristelikNasionale Onderwys, waarvan hy 'n vurige voorstander was. Die Skotse Wet van 1872 het die godsdiensonderrig iets anders as die Engelse Wet van 1870 gereël. Die Skotse Skoolrade was heeltemal vry ten opsigte van die beheer van hul skole. Hulle mog, binne die ure afgesonder vir godsdiensonderrig, enige godsdienstige formule aanvaar soos hulle verkies. Hulle was dus nie onderworpe aan enige beperking soos in Engeland uit vrees vir uitgerekte sektariese twiste of verontregting nie.

Die Transvaalse Onderwyswet van S. J. du Toit-Wet No. 1 van 1882-bevat ' $n$ breedvoerige Godsdiensklousule. Hierdie Klousule, No. 2 van die Wet, lui so: „Erkennende dat het Godsdiensonderwijs als zoodanig thuis behoort by die Kerk en niet by de Staat, zoo eischt de Regering slects dat, in alle van Regeringswege ondersteunde scholen, het burgerlijke Onderwijs behoorlijk gegeven worde: (a) in christelijken geest; (b) waarbij begrepen is het openen en sluiten der School met Gebed en het lezen van Gods Woord en de behandeling der Bijbelgeschiedenis binnen de Schooluren; (c) terwijl het bepaald confessioneel onderwijs aan de respectieve Kerkbesturen wordt overgelaten; (d) waarin de verschillende Schoolbesturen naar omstandigheden zullen behulpzaam zijn, door de vrijstelling van schoollokalen als andersins; (e) waarbij de Regering de wenschelijkheid uitspreekt, dat de verschillende Gemeenten en Kerkeraden zelf, zooveel mogelijk is, het initiatief nemen in het stichten van scholen en het kiezen van schoolcommissien". Hierdie Klousule het die Transvaalse Afrikaner bevredig, al het dit nog nie aan alle prinsipiële eise voldoen nie en 'n Gewetensklousule daarin ontbreek.

Met die aanvaarding van die Superintendentskap het prof. dr. N. Mansvelt-'n Nederlander van afkoms-die Godsdiensklousule in Wet No. 8 van 1892 verskerp. In Klousule 1 van die Wet word die woord "Christelik" vervang deur die woord „Protestants-Christelik" en 1(b) lees dan: „voor zoo ver zij (de Staat) zich geroepen acht toe te zien dat hare toekomstige burgers de vereischte Protestantsch-Christelijke opvoeding ontvangen". In Klousule 2 (die Godsdiensonderwys-Klnusule) word een woord ingevoeg en 'n ander gewysig. Voor „Godsdienutonderwijs" word nou ingevoeg ,leerstellig" en onder (a) word „christelijken" verander tot "Protestantsch-Christelijken”. Klousule 2(e) van die Wet van 1882 kom nie voor in die Wet van 1892 nie. Die Gods- 
diensklousule in die onderwys is dus skerper gestel: die geloofsbelydenis word beperk tot die Protestantse en die aandeel van die Kerk ingekort.

Dit het die blywende reëling gebly tot die uitbreek van die Tweede Vryheidsoorlog.

4.

Na die vredesluiting in 1902 is die Transvaalse anderwys opnuut georganiseer en gereglementeer.

Die eerste wetgewing het gekom deur die Transvaal Ordinance No. 7 of 1903. Hierdie Ordonnansie bevat 'n uitvoerige Godsdiensklousule, waarvan E. B. Sargant die ontwerper en verdediger was.

Klousule 5 van die Wet bevat drie onderdele. Dit lui so:

,(1) In all schools established under Section one clause (b) of this Ordinance in which elementary education is provided not being expressly established for the children of persons belonging to other than christian bodies, instruction shall be given by the teachers in Bible History for periods not exceeding in all two hours a week. Such instruction may be given in the Dutch language.

(2) Whenever parents or guardians request on behalf of their children that supplementary religious instruction may be given according to the specific doctrines of the denominations to which the said parents or guardians belong, opportunity shall be afforded to minister of religion recognised by Government to give supplementary instruction of this character in the usual school hours and within such portion of the school premises as may be set apart for the purpose. Provided always that no scholar shall be required to be present whose parent or guardian has not expressed a desire for such instruction; provided further that such instruction may be given in the Dutch language.

(3) No scholar shall be required to attend such instruction in Bible History or any other religious instruction or observance if exemption therefrom is requested by his parent or guardian".

Die Sargant-klousule is slegs van verbygaande belang, want in 1907 is die hele Onderwyswetgewing opnuut geformuleer, en wel deur genl. J. C. Smuts, destyds Koloniale Sekretaris vir Transvaal. Die Smuts-klousule is van beslissende betekenis, omdat dit die Transvaalse onderwys van 1907 tot 1953 gereël het. Klousule 34 dan bepaal Godsdiensonderwys op die openbare skool.

Die voorgaande geskiedenis sal die Klousule goed verstaanbaar maak. Genl. Smuts self was 'n voorstander van 'n liberalistiese lewens- 
filosofie. Hy het dieselfde standpunt ingeneem as die wetgewers in Engeland in 1870: Gee aan die skole 'n godsdiensonderwys sonder spesifieke dogma en sonder gewetensdwang.

Die Wet, No. 25 van 1907, is nog in Hollands gestel en Klousule 34 lui in sy geheel so:

„In elke openbare school

(1) zal de schooldag geopend worden met gebed en het lezen van een gedeelte uit den Bijbel;

(2) behalve als hierin later bepaald zal onderricht in Bijbelsche geschiedenis gegeven worden in de Engelsche Hollandsche of eenige andere Europeesche taal en waar mogelijk zal zulk onderricht gegeven worden binnen het eerste half uur van elken schooldag; met dien verstande dat niets in dit of het laatst-voorafgaande subartikel vervat van toepassing zal zijn op scholen in de eerste plaats opgericht en in stand gehouden ten behoeve van of hoofdzakelijk bezocht door kinderen van niet-Christelijk ouders tenzij zulk een school bezocht wordt door kinderen van Christelijke ouders in welk geval voorziening gemaakt zal worden op een schriftelijke aanvrage van de ouders van zoodanige laatstgenoemde kinderen voor hun onderricht in Bijbelsche geschiedenis ;

(3) zal geen kind wiens ouder schriftelijk kennis heeft gegeven aan het hoofd der school van zijn wensch dat zulk kind geen onderricht in Bijbelsche geschiedenis ontvangen zal, verplicht zijn zulk onderricht te ontvangen;

(4) zal geen leer of dogma aan eenige godsdienstige gemeente of secte eigen onderwezen worden;

(5) zal geen onderricht in Bijbelsche geschiedenis gedurende schooluren gegeven worden door eenig persoon anders dan een onderwijzer die aan de staf van zulk school verbonden is;

(6) zal geen hoofd-onderwijzer of eenig assistent-onderwijzer die verantwoordelijk is voor het algemeene welzijn van een klasse of afdeeling of departement toegelaten worden tot of aangehouden worden bij den staf tenzij hij bereid is op nauwgezette wijze onderricht in Bijbelsche geschiedenis te geven zooals vereischt krachtens dit artikel of den Directeur eenig bezwaar voor te leggen dat hij mocht hebben om zoodanig onderricht op zich te nemen; 
(7) zal de tijd aan onderricht in Bijbelsche geschiedenis in de verschillende standaarden te worden besteed zijn zooals bij regulatie bepaald."

Hierdie Klousule is skerp veroordeel deur die ortodokse Afrikaner, o.a. in die brosjure van dr. J. D. du Toit „Christelijk Onderwijs met of zonder Dogma".

Maar alle teenstand het niks gebaat nie. Daarenteen het die ortodokse onderwyser in al die jare Bybelse Geskiedenis onderrig, en dit in die lig van die Nederlandse Geloofsbelydenis verstaan en verduidelik. Die Klousule het in die Transvaal presies net so gewerk soos dit in Engeland gewerk het. W. O. Lester Smith sê in sy „Education in Great Britain": "This curious settlement (the Cowper-Temple Clause) has proved so durable that it still survives; and, amplified and improved, it constitutes the basis of the concordat embodied in the Education Act of 1944", terwyl Canon Spencer Lesson in sy "Christian Education" sê dat die „Clause gives a wide opportunity for christian teaching, and that opportunity has been taken full advantage of by numbers of teachers in council schools, with due regard for the law and for freedom of conscience". Feitlik is dit ook waar van die Smuts-Klousule, maar in werklikheid is die uitvoering van subklousule (4) onmoontlik, want niemand kon enige onderwys, enige godsdiensonderwys ingesluit, gee sonder ' $n$ bepaalde lewens. en wreldbeskouing as grondslag en beginsel d.xarvan nie. Die subklousule (4) is onuitvoerbaar maar tog ook dreigend. Die deur is oop vir vervolging, al het daar in die afgelope halfeeu nog geen vervolging plaasgevind nie.

5.

Die besware van ortodokse kant teen die Smuts-klousule het bly staan.

Met die verloop van jare het die oorspronklike Smutswet baie wysigings ondergaan. Teen 1950 was dit so verander en gelap, dat 'n konsolidasie van die wetgewing dringend noodsaaklik geword het. So het daar in 1953 onder administrateur Wm. Nicol 'n nuwe Onderwysordonnansie van krag geword, nl. Provinsiale Ordonnansie No. 29.

Die nuwe Godsdiensklousule (No. 53 van die Ordonnansie) lui so:

„(1) In elke openb.are skool begin die skooldag met gebed en die lees van 'n gedeelte uit die Bybel. 
(2) Behoudens die bepalings van hierdie hoofstuk word godsdiens onderrig in elke openbare skool vir en op sodanige tye gegee as wat die Direkteur mag voorskryf: Met dien verstande dat die onderrigtyd in laer skole minstens twee uur per week en in middelbare skole minstens een uur per week moet wees: Voorts met dien verstande dat niks in hierdie subartikel of subartikel (1) vervat van toespassing is nie op 'n openbare skool wat hoofsa:zklik ingestel is en onderhou word vir of grotendeels besoek word deur kinders van nie-Christen-ouers tensy sodanige skool deur kinders van Christen-ouers besoek word, en in hierdie geval moet daar op skriftelike aansoek van die Christen-ouers voorsiening gemaak word vir hul kinders om godsdiensonderrig te ontvang.

(3) Indien die ouer van 'n leerling wat enige openbare skool bywoon die hoofonderwyser daarvan skriftelik versoek dat die leerling vrygestel word van godsdiensonderrig, moet die leerling aldus vrygestel word totdat die versoek teruggeterk word.

(4) Geen bepaalde leer of dogma wat onderskeidend is van 'n besondere godsdienstige gesindte of sekte, mag in enige openbare skool gedoseer word nie.

(5) Geen onderrig in Bybelgeskiedenis mag in enige openbare skool gedurende skoolure gegee word nie deur enigiemand anders as 'n onderwyser wat lid is van die personeel van sodanige skool.

(6) Geen hoofonderwyser of enige assistent-onderwyser wat vir die algemene welsyn van 'n klas of groep of afdeling verantwoordelik is, word as lid van die personeel van 'n openbare skool toegelaat of gehou nie, tensy hy of bereid is om sonder gewetensbeswaar godsdiensonderrig te gee soos by hierdie artikel vereis, of aan die Direkteur enige beswaar voorlê wat hy daarteen mag hê om sodanige onderrig te gee."

Die vraag is nou of die ortodokse Afrikaner iets gevorder het ten opsigte van die godsdiensonderrig in openbare skole.

Om die vraag te beantwoord moet ons die hele Ordonnansie bestudeer. En dan sal ons antwoord beslis bevestigend wees, al het ons dan nog nie ons ideaal van godsdiensonderrig op 'n staatsondersteunde skool van ons eie gees en rigting bereik nie.

Ons moet in ag neem dat die Ordonnansie uitgevaardig is vir die openbare skool in Transvaal, 'n skool waarin kinders uit alle lae van die bevolking en van verskillende gees en rigting gesamentlik onderrig ontvang. So 'n ,gemengde" skool kan nooit 'n ideale skool na Gereformeerde oortuiging wees nie. Dit is en bly per slot van rekening op sy 
allerbeste 'n Christelike Openbare Skool sonder 'n eie, spesifieke gees en rigting.

Die Ordonnansie dan lê neer in Klousule 3(1) (d) (ii) : „Die Provinsiale onderwysbeleid word . . . so beplan dat . . . kinders in ooreenstemming met die wense van hul ouers opgevoed moet word". In Klousules 47-57 word die samestelling, verkiesing en bevoegdhede en pligte van skoolkomitees beskryf. Die Skoolkomitee word deur die ouers (of voogde) van skoolgaande kinders gekies. Die ouers kan hul wense aan hul skoolkomitee bekend maak en vra dat daaraan voldoen word. Klousule 50 (c) gee aan die Skoolkomitee die bevoegdheid en plig om aan die aanstelling van onderwysers vir die skool deel te neem. 'n Skoolkomitee kan dus sorg dat hy onderwysers na die wense van die ouers vir sy skool aangestel kan kry. Klousule 53(5) bepaal dat godsdiensonderrig op skool net deur 'n personeellid van die skool gegee mag word. As 'n komitee die regte onderwyser aanbeveel, kan die ouers verseker wees van die regte godsdiensonderwys. Klousule 53(b) sê uitdruklik dat 'n onderwyser sonder gewetensbeswaar godsdiensonderrig aan sy skool moet gee, so nie, moet hy aan die Direkteur sy besware teen die gee van sodanige onderrig voorlê.

Die slotsom van die saak is dus dit. Ouers kan die regte Skoolkomitee kies, die Skoolkomitee kan die regte onderwyser aanbeveel, die regte onderwyser kan na die wense van die ouers die regte godsdiensonderrig aan hul kinders gee.

Nou bly daar net een vraag oor: wat beteken Klousule 53(4) eintlik?

Ordonnansie No. 29 van 1953 is 'n stuk wetgewing vir die openbare skool. Dit maak Christelike godsdiensonderwys verpligtend, maar met gewetensvryheid vir nie-Christene. Ons kan met reg beweer dat die Transvaalse skool 'n Christelike Openbare skool is. Is Klousule 53(4) nou in stryd daarmee? Die Klousule het 'n positiewe sowel as 'n negatiewe aspek. Negatief, verbied dit bepaalde dogma of leer onderskeidend van 'n besondere godsdienstige gesindte of sekte. Positief, gee dit opening vir die Gereformeerde Geloofsbelydenis, omdat dit nie onderskeidend is van 'n besondere godsdienstige gesindte of sekte nie - -dit tog is die belydenis van die drie Hollands-Afrikaanse Kerke. Ek beweer dus dat binne die raamwerk van die Transvaalse openbare skoolstelsel Gereformeerde ouers deur middel van hul Skoolkomitee Gereformeerde godsdiensonderrig vir hul kinders kan verseker! Meer kan 
inderdaad van 'n openbare skoolstelsel nie verwag word nie!

Voorstanders van C.N.O. bly as idearal stel 'n staatsondersteunde skoolstelsel, waaronder hulle hul eie skool kan kry. Intussen moet hulle die volste gebruik makk van die regte en voorregte hulle aangebied deur ons Wet.

J. CHR. COETZEE. 